\title{
A CASE OF UNUSUALLY EXTENSIVE RUPTURE OF THE CORNEO-SCLERAL MARGIN
}

\author{
BY \\ Leslie Buchanan, M.D. \\ SURGEON AND INTERIM PATHOLOGIST, THE GLASGOW EYE INFIRMARY
}

THE following case is worthy of note, in so far as the extent of the injury is greater than usual and than has been hitherto described.

J. McP., a farm worker, was struck on the right eye by a cow's horn, and was sent to the Glasgow Eye Infirmary at once. It was found that he had a large rupture of the corneo-scleral margin, and that the eye had no perception of light.

A few days were allowed to elapse, as there had been extensive haemorrhage into the orbit, and the eye was excised six days after the injury.

The eye was examined, and found to be in a very collapsed condition, all the normal contents having been either extruded or so much displaced and damaged that the eye was manifestly useless. The cornea was found to be hanging by a comparatively narrow portion of the lower margin, and free all round elsewhere. Measurements were carefully made; and it was found that the corneal diameter is $13.5 \mathrm{~mm}$. The arc of detachment is external, superior, and internal, and the arc of remaining attachment, which only measures $9.5 \mathrm{~mm}$., is situated at the lower and inner part. As the circumference of the cornea is approximately $40.8 \mathrm{~mm}$., the extent of the rupture is greater than three-quarters of the corneal circumference. The rupture is smoothly and cleanly defined as if made by a punch, and is situated at a distance not more than $1 \mathrm{~mm}$. from the apparent corneo-scleral margin. It is probable that the rupture has been made by a combination of direct and indirect violence.

This is by far the largest rupture which has ever come to my notice, as a rupture of even half the extent of the corneal circumference is very rare. Few writers say much regarding. the extent of ruptures of the sclera, but Praun (of Darmstadt) mentions that they may be as large as half the corneal circumference. 